\title{
Summary
}

The condition of familial macular coloboma is found in five members of a family.

The next generation so far shows no similar defects. The previous generation unfortunately cannot be fully investigated but the suggestion is that the defect in this family derives from the maternal side. Further observations in the side branches on this side of the family may possibly provide instances of the same defect.

\section{EYELASH IN THE ANTERIOR CHAMBER FOLLOWING THE REMOVAL OF AN INTRA-OCULAR FOREIGN BODY}

BY

\author{
W. J. B. RIDDELI
}

GLASGOW

THE interest of this case lies in the possibility that the eyelash entered the eye after the removal of an intra-ocular foreign body. The patient was a man aged 19 years, who received what he assumed to be a trivial injury to his left eye at his work in July, 1936. Shortly after the accident he went on holiday and discovered that the vision in the eye was failing. I saw him early in August, 1936, for the first time. The right eye was normal and has remained so. The left eye was white and showed no sign of inflammation and was not injected. In the central area of the cornea there was a small healed punctured wound. The anterior chamber was of normal depth, the pupil was active and the iris showed no sign of injury. A traumatic cataract was present and in the lens substance a small metallic foreign body was seen. The vision was reduced to hand movements. He had no pain and regarded the injury as trivial until he noticed the sight failing.

On August 12, 1936, the foreign body was removed through a straight keratome section by means of a hand magnet. A guarded speculum was used and no instrument entered the eye except the straight keratome. Before the section was made the foreign body was brought forward through the lens substance but could not be got into the anterior chamber because the wound in the lens capsule had sealed. Consequently a small opening in the capsule was made with the point of the keratome before withdrawal. 'This opening was several millimetres below the section and no capsule was drawn up. The section was made without loss 
of aqueous. The foreign body was easily removed. The conjunctival sacs were irrigated before the operation but not afterwards. The method employed followed that described by Whiting and Goulden ${ }^{1}$ and no iridectomy was required.

Progress was uneventful for a day or two. From the third day onwards a violent reaction developed. This was more marked than could be accounted for by the swollen soft lens matter which had come forward. On August 19, a paracentesis was performed. This did not improve matters and the eye remained red and painful. The question of excision was considered seriously but towards the end of the month the eye was beginning to settle down. The anterior chamber contained masses of yellowish soft lens matter. The patient was discharged from hospital on September 14. In October, 1936, the lens matter had absorbed sufficiently to permit of detailed examination. The vision with a plus 11.0 D.sph. was $6 / 24$ and fundus details could be seen. In the lower part of the anterior chamber, lying horizontally upon the surface of the iris an eyelash was observed. The eye remained quiet and in January, 1937, the vision was $6 / 18$ with an aphakic correction. There is no gap in the posterior capsule. $\mathrm{He}$ has had no more pain or discomfort and the vision has been maintained (May, 1937).

The patient had very luxuriant eyelashes which fell out readily and were frequently noticed on his dressings. I am of the opinion that a loose eyelash, lying unobserved in the fornix entered the eye after the removal of the foreign body and before the keratome section had time to seal up. If entry had been effected at the time of the accident some inflammatory reaction would have been expected. There was none. Both before and during the operation the eye was under close scrutiny by myself and my assistant; nothing untoward was observed. Apart from the necessity of making an opening in the anterior lens capsule when the section was made, the case did not differ from many others which I have had to operate upon since my apprenticeship in these matters at Moorfields. This patient was shown to the members of the Scottish Ophthalmological Club in October, 1936, and the majority of opinion was in favour of leaving the eyelash alone. This view is confirmed by some of the cases quoted by Savin. ${ }^{2}$

A fortuitous intra-ocular eyelash is an uncommon occurrence and is a possible cause of obscure post-operative inflammation.

\section{REFERENCES}

1. Whiting, M. H. and Goulden, C. B.-Brit. Jl. of Ophthal., Vol. I, p. 32, 1917.

2. Savin, L. H.-Brit. Jl. of Ophthal., Vol. XX, p. 609, 1936. 